\title{
PENGUJIAN PARAMETER FISIK SABUN MANDI CAIR DARI SURFAKTAN SODIUM LAURETH SULFATE (SLES)
}

\author{
Devita Cahyaningsih ${ }^{1)}$, Nina Ariesta ${ }^{2)}$, Rizki Amelia ${ }^{3)}$ \\ ${ }^{1)}$ Kimia, FMIPA, Universitas Nusa Bangsa, Bogor, Indonesia \\ ${ }^{2)}$ Kimia, FMIPA, Universitas Nusa Bangsa, Bogor, Indonesia \\ ${ }^{3)}$ PT Gizi Indonesia, Jl. Veteran II, RT. 004 RW. 02 Teluk Pinang, Ciawi, Bogor, Indonesia \\ *email : ariestanina14@gmail.com
}

\begin{abstract}
PHYSICAL PROPERTIES OF LIQUID SHOWER SOAP CONTAINED OF SODIUM LAURETH SULFATE (SLES) SURFACTANT
\end{abstract}

\begin{abstract}
Soap could be produced by saponification and neutralization process. It was contained of fatty acid, KOH, glycerin, and surfactan. The properties of surfactant determined physical properties of soap as the quality parameter of soap. The study was conducted to examine some of the physical parameters of liquid bath soap (stability test: color, aroma, viscosity, homogeneity, viscosity and $\mathrm{pH}$ ) in accordance with applicable standards. The study was conducted using soap which was contained of SLES surfactants (Sodium Laureth Ether Sulfate). The results were pH 8.61 and viscosity 55254 cps on stability test include oven test, cycle test, room test, and sun test.
\end{abstract}

Keywords: liquid shower, Sodium Laureth Ether Sulfate, soap stability

\begin{abstract}
ABSTRAK
Sabun yang merupakan salah satu kosmetik pembersih dapat dibuat melalui dua proses, yaitu saponifikasi dan netralisasi. Sabun tersusun dari berbagai bahan, seperti asam lemak, KOH, gliserin, dan surfaktan. Sifat surfaktan dalam sabun menentukan sifat fisik dari sabun yang dihasilkan dan sebagai salah satu faktor penentu mutu. Tujuan dari penelitian ini adalah untuk menguji beberapa parameter fisik sabun mandi cair (uji stabilitas: warna, aroma, kekentalan, homogenitas, viskositas dan $\mathrm{pH}$ ) sesuai dengan standar yang berlaku, sehingga dapat dilanjutkan ke tahap pengujian berikutnya. Penelitian ini dilakukan dengan menggunakan surfaktan SLES (Sodium Laureth Ether Sulfate). Beberapa parameter fisik terukur adalah $\mathrm{pH} 8,61$ dan viskositas $55254 \mathrm{cps}$ pada pengujian stabilitas meliputi oven test, cycle test, room test, dan sun test.
\end{abstract}

Kata Kunci: sabun cair, Sodium Laureth Ether Sulfate, stabilitas sabun

\section{PENDAHULUAN}

Sabun tersusun dari berbagai bahan, seperti asam lemak, $\mathrm{KOH}$, gliserin, dan surfaktan. Menurut Cavitch (2001), setiap asam lemak memberikan sifat yang berbeda pada sabun yang dihasilkan. Sabun yang dihasilkan dari asam lemak dengan bobot molekul kecil akan lebih lunak daripada sabun yang dibuat dari asam lemak dengan bobot molekul besar.Surfaktan atau surface active agents atau wetting agents merupakan bahan organik yang berperan sebagai bahan aktif pada detergen, sabun, dan shampo. Surfaktan dapat menurunkan tegangan permukaan sehingga memungkinkan partikel-partikel yang menempel pada bahanbahan yang dicuci terlepas dan mengapung atau terlarut dalam air (Effendi, 2003). Sifat surfaktan dalam sabun menentukan sifat fisik dari sabun yang dihasilkan dan sebagai salah satu faktor penentu mutu. Penggunaan surfaktan dalam produk sabun cair dapat mempengaruhi mutu produk baik secara kegunaan atau fungsinya terhadap kulit maupun bentuk fisik produk tersebut (Sujianti, 2010). Untuk mengetahui mutu produk sabun cair berdasarkan sifat fisiknya dapat 
dilakukan pengujian dengan beberapa parameter, diantaranya warna, bau, homogenitas, viskositas, dan $\mathrm{pH}$ serta kestabilannya melalui uji stabilitas. Kemudian hasil uji produk tersebut dibandingkan dengan standar atau acuannya.

Pengujian mutu terhadap sampel sabun cair ini sangat penting dilakukan karena hasil semua pengujian tersebut akan menentukan apakah produk tersebut dapat dibuat pada skala yang lebih besar. Jika hasil pengujian tersebut telah memenuhi standar, maka produk tersebut dapat dibuat pada skala produksi untuk dijual di pasaran. Ketidak sesuaian mutu produk dengan standar yang berlaku dapat berpotensi menimbulkan masalah dikemudian hari, oleh karena itu pengujian sampel produk harus dilakukan sebaik mungkin.

\section{BAHAN DAN METODE}

Bahan

Bahan yang digunakan pada penelitian ini terdiri dari sampel dimana formula F1, sabun mandi cair menggunakan asam lemak, gliserin, $\mathrm{KOH}$, dan SLES (Sodium Laureth Ether Sulfate) sebagai surfaktan. Sampel F1 simplo.

Alat

Alat yang digunakan adalah Viskometer Brookfield, ultimixe mixer homogenizer, $\mathrm{pH}$ meter, oven, lemari pendingin dan termometer.

\section{Metode}

1. Evaluasi sampel meliputi:

a. Penampilan fisik

Masing-masing sampel dan standar diambil sedikit dari wadahnya, kemudian dituang diatas plat keramik berwarna dasar putih. Sampel diamati warnanya. Warna sampel harus sama dengan warna standar.

\section{b. Aroma}

Pengujian aroma khas produk dilakukan secara organoleptik. Masingmasing sampel dicium aromanya. Aroma sampel harus sama dengan aroma standar.

c. Homogenitas

Masing-masing sampel diambil sedikit dari wadahnya, kemudian dituang di atas plat keramik berwarna dasar putih. Pengaduk panjang di letakkan di atas sampel lalu di tarik satu arah sehingga terbentuk lapisan tipis sampel. Homogenitasnya diamati dengan memastikan bahwa lapisan yang terbentuk rata dan tidak ada partikelpartikel yang terbentuk.

d. $\mathrm{pH}$

Masing-masing sampel ditempatkan dalam wadah. Elektroda $\mathrm{pH}$ dicelupkan kedalam sampel lalu dicatat nilai $\mathrm{pH}$ setelah muncul tanda ready pada layar. Elektroda dibersihkan dengan alkohol $70 \%$ dan dibilas dengan aquadest terlebih dahulu sebelum dilanjutkan ke pengukuran sampel berikutnya.

e. Viskositas

Masing-masing sampel ditempatkan dalam piala gelas $200 \mathrm{~mL}$. Kemudian diukur viskositasnya dengan alat viskometer Brookfield menggunakan spindle no. 4 dan speed $3 \mathrm{rpm}$ dicatat. Nilai viskositas serta akurasinya atau \% torsi (harus diatas 50\%).

2. Uji Stabilitas

a) Temperatur Ruang (Room Test)

Sampel disimpan pada temperatur ruang $\left(23^{\circ} \mathrm{C}-32^{\circ} \mathrm{C}\right)$, selama 3 bulan dan diamati perubahan fisiknya dan $\mathrm{pH}$ diukur setiap bulan dengan kertas $\mathrm{pH}$ universal. Perubahan fisik yang diamati meliputi warna, bau, kekentalan, dan homogenitas

b) Temperatur Oven (Oven Test)

Sampel disimpan dalam oven pada temperatur $45^{\circ} \mathrm{C}$, selama 3 bulan dan diamati perubahan fisiknya dan $\mathrm{pH}$ diukur setiap bulan dengan kertas $\mathrm{pH}$ universal. Perubahan fisik yang diamati meliputi warna, bau, kekentalan dan homogenitas

c) Paparan Sinar Matahari Langsung (Sun Test)

Sampel dipapar di bawah sinar matahari, selama 2 minggu. Efektivitas sinar matahari dicatat dengan mengukur temperatur pagi, siang dan sore (pukul 09.00 , pukul 12.00 , dan pukul 16.00) dan diamati perubahan fisiknya. Nilai $\mathrm{pH}$ diukur setiap bulan dengan kertas $\mathrm{pH}$ universal. Perubahan fisik yang diamati meliputi warna, bau, kekentalan dan 
d) Cycle Thaw Test

Sampel disimpan dalam oven (temperatur $45^{\circ} \mathrm{C}$ ) selama 24 jam, kemudian dipindahkan ke dalam freezer (temperatur $-10^{\circ} \mathrm{C}$ ) selama 24 jam (dapat disebut 1 siklus). Hal ini dilakukan selama 1 minggu. Diamati perubahan fisiknya pada setiap perpindahan.

\section{HASIL DAN PEMBAHASAN}

Sabun mandi cair sampel F1 yang dihasilkan memiliki karakteristik berwarna putih mengkilat (putih pearly), homogen, smooth dan aroma khas (Parfume tercium). Sabun dibuat melalui dua proses, yaitu saponifikasi dan netralisasi. Proses saponifikasi terjadi karena reaksi antara trigliserida dengan alkali, sedangkan proses netralisasi terjadi karena reaksi asam lemak bebas dengan alkali. Pada proses saponifikasi akan diperoleh produk samping yaitu gliserol, sedangkan proses netralisasi tidak menghasilkan gliserol (Spiess,1996). Proses saponifikasi terjadi pada suhu 80$100^{\circ} \mathrm{C}$.

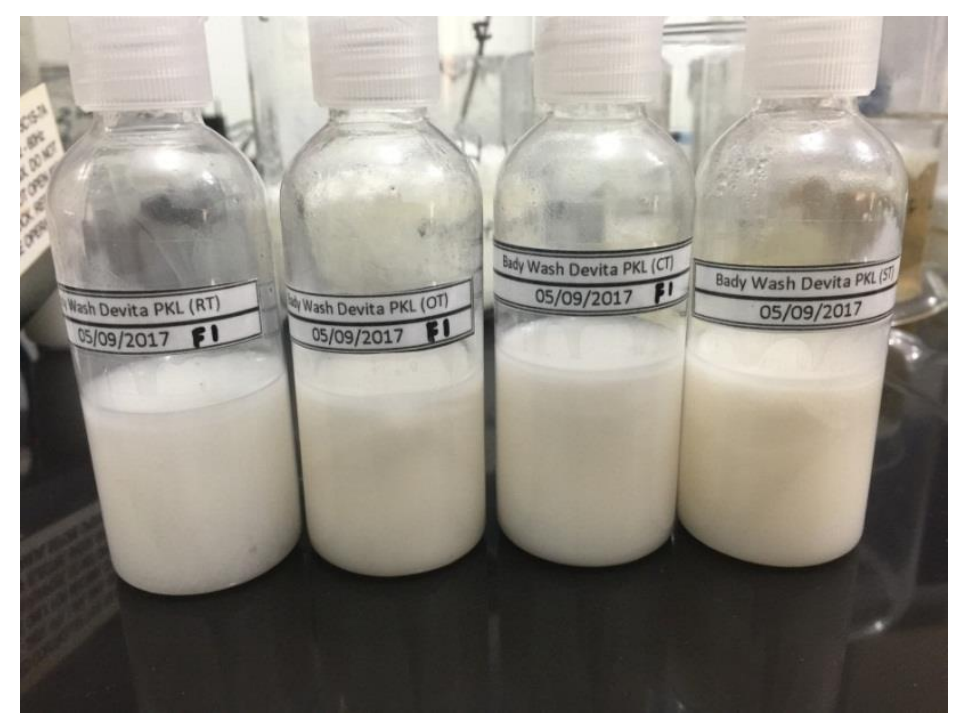

Gambar 1. Sampel sabun mandi cair F1 (Sabun menggunakan surfaktan Sodium Laureth Ether Sulfat (SLES))

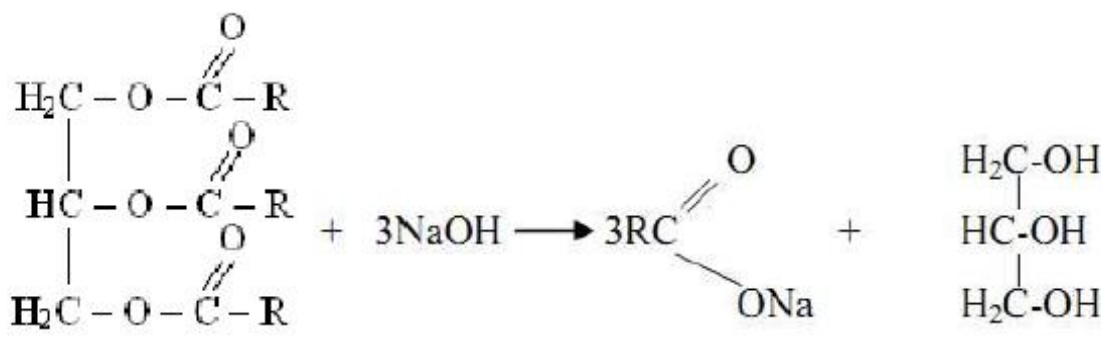

Trigliserida Alkali Sabun Gliserol

Gambar 1. Reaksi kimia pada proses saponifikasi 


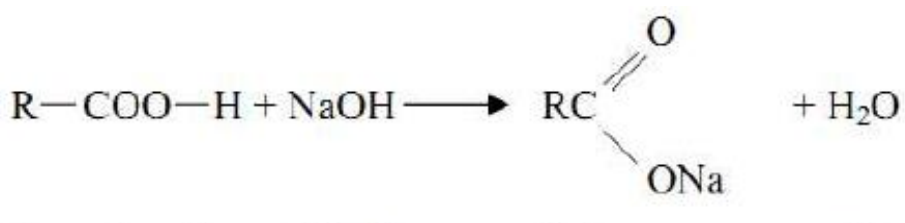

\section{Asam lemak Alkali Sabun Air}

Gambar 2. Reaksi kimia pada proses netralisasi

Pengujian sabun dilakukan untuk untuk memastikan mutu sampel produk tersebut sesuai dengan standar yang berlaku, sehingga dapat dilanjutkan ke tahap pengujian berikutnya. Jika semua hasil pengujian telah memenuhi standar, maka proses pembuatan produk dapat dilakukan pada skala produksi. Pengujian yang dilakukan meliputi uji stabilitas produk dipercepat (accelerated test) produk seperti uji pemeriksaan fisik (bentuk,aroma dan warna), uji $\mathrm{pH}$ dan uji viskositas.

Warna awal sabun putih mengkilap berubah menjadi kekuningan pada oven test mulai minggu ke-3. Pada percobaan dengan paparan sinar matahri, perubahan warna putih kekuningan terjadi mulai minggu ke- 2 . Stabilitas warna sabun telihat pada cycling test dan room temperature test hingga minggu ke-3 warna tiduk berubah menjadi kekuningan. Perubahan warna yang signifikan terjadi pada penyimpanan suhu tinggi dan paparan sinar matahari, dimana terlihat sampel F1 berubah warna menjadi warna putih kekuningan mengkilap. Hal ini dapat disebabnya adanya faktor suhu yang tinggi sehingga dapat mempercepat reaksi kimia karena tiap kenaikkan suhu sebesar $10^{\circ} \mathrm{C}$ dapat mempercepat reaksi kimia 2 sampai 3 kalinya (Djajadisastra, 2004). Tingkat oksidasi asam lemak, sangat ditentukan oleh perubahan suhu dan panas asam lemak serta sangat menentukan intensitas warna atau stabilitas warna asam lemak yang dihasilkan (Ketaren,1986).

\section{Karakteristik Sabun Mandi Cair}

Sabun mandi cair sampel F1 yang dihasilkan memiliki karakteristik berwarna putih mengkilat (pearly white), homogen, smooth dan aroma khas (Parfume tercium).

\section{a. Uji Derajat Keasaman (pH)}

Pada uji stabilitas suhu tinggi, nilai $\mathrm{pH}$ mempunyai kecenderungan semakin naik karena terjadinya proses hidrolisis adanya peningkatan suhu. Semakin tinggi suhu maka semakin cepat proses hidrolisis, karena suhu mempercepat reaksi (Pangajuanto, 2009). Jika lemak dihidrolisis akan menjadi asam lemak dan gliserol. Sifat asam lemak itu bersifat asam karena adanya penambahan $\mathrm{KOH}$ yang bersifat basa dan $\mathrm{KOH}$ lebih kuat dari asam lemah maka pH sabun menjadi basa. Karena adanya faktor suhu maka reaksi hidrolisis dipercepat dan $\mathrm{pH}$ akan semakin tinggi atau meningkat (Pangajuanto, 2009).

Tabel 1. Data Perbandingan Hasil Analisis Sabun Mandi Cair sampel F1 dengan Standar

\begin{tabular}{ccc}
\hline Parameter & Standar & Sampel F1 \\
\hline Bentuk & Cairan Kental & Cairan Kental \\
Warna & Putih Mengkilat & Putih Mengkilat \\
Bau & Khas & Khas \\
Homogenitas & Homogen & Homogen \\
pH & $8,0-10,0$ & 8,61 \\
Viskositas & $10000-65000 \mathrm{cps}$ & $55254 \mathrm{cps}$ \\
\hline
\end{tabular}

Keterangan :

Sampel F1 : Sabun menggunakan surfaktan Sodium Laureth Sulfate Ether (SLES) 


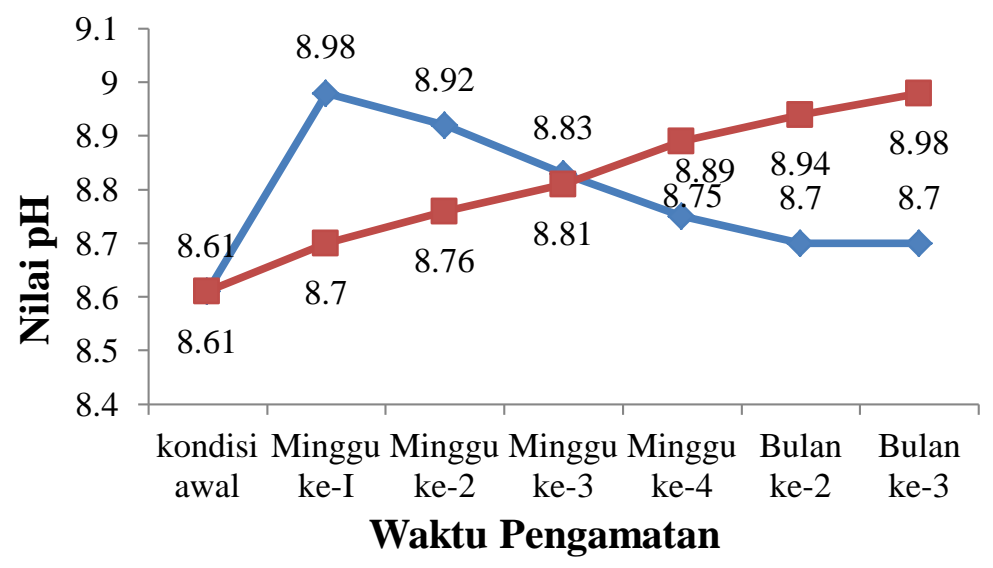

Gambar 3. Hasil Pengamatan pH Accelerated Test Sabun Mandi Cair Sampel F1( $R$ Room Test , Oven Test)

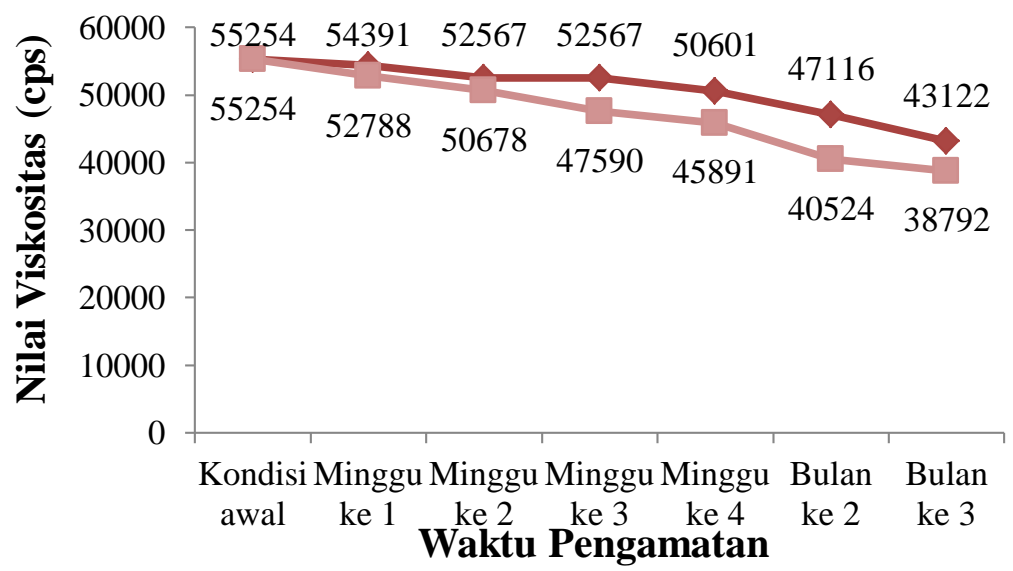

Gambar 2. Hasil Pengamatan Viskositas Accelerated Test Sabun Mandi Cair Sampel F1 ( Room Test, Oven Test)

Nilai $\mathrm{pH}$ pada kondisi Sun Test dan Cycle Test memiliki nilai $\mathrm{pH}$ yang stabil Perubahan nilai $\mathrm{pH}$ pada sediaan tidak signifikan dan masih masuk ke dalam nilai $\mathrm{pH}$ sesuai standar, sehingga kedua sampel tersebut dapat dikatakan stabil. Nilai $\mathrm{pH}$ awal dari masing-masing sampel hingga setelah pengujian baik dalam kondisi suhu ruang dan suhu tinggi yaitu 8,50-8,98.

\section{b. Uji Viskositas}

Penurunan viskositas pada suhu ruang dan suhu tinggi ini dapat disebabkan karena terdapat gliserin dan sorbitol, dalam konsentrasi tinggi $(>10 \%)$ dapat menyebabkan terbentuknya titik-titik air (fenomena sweating) pada produk jika disimpan dalam lingkungan yang lembab karena gliserin memiliki sifat higroskopis memiliki tiga gugus hidroksil yang membentuk ikatan hidrogen dengan molekul air. Ini adalah masalah yang umum terjadi pada sabun mandi cair yang menggunakan humektan sebagai bahan baku. Masalah ini tidak terjadi pada sabun yang menggunakan bahan-bahan tersebut dengan konsentrasi kurang dari 5\% (George dan Serdakowski, 1996). Pengaruh gliserin yang bersifat higroskopis yaitu mampu menyerap uap air dari luar sehingga kandungan air dalam sediaan semakin banyak (Rowe et a.l, 2009). Penambahan konsentrasi surfaktan ini dapat meningkatkan viskositas sabun cair yang dihasilkan. Akan tetapi jika penambahannya yang lebih dari $30 \%$ menyebabkan produk berbentuk gel atau pasta (Shipp,1996). Kandungan air yang banyak menyebabkan sediaan sabun mandi cair menjadi semakin 
encer dan viskositasnya semakin kecil. Penurunan viskositas ini dapat disebabkan oleh kenaikan ukuran diameter partikel yang menyebabkan luas permukaan semakin kecil dan mengakibatkan viskositas menurun.

Viskositas sabun mandi cair pada uji stabilitas kondisi suhu tinggi (oven test) mengalami penurunan tiap siklusnya pada sampel. Hal ini disebabkan oleh pengaruh suhu yang diberikan yang membuat sediaan semakin encer saat penyimpanan suhu tinggi $\left(40^{\circ} \mathrm{C}\right)$. Uap air dari suhu tinggi mampu berinteraksi dengan sediaan yang membuat volume air sediaan bertambah yang menyebabkan nilai viskositas sediaan semakin kecil (Zulkarnain et al., 2013). Suhu merupakan faktor yang mempengaruhi viskositas, kekentalan suatu zat berkurang bila dipanaskan. Kenaikkan suhu akan memperbesar jarak antarmolekul sehingga kekuatan gesekan antarmolekul berkurang dan kekentalan cairan akan berkurang. Semakin kecil gaya gesek antarmolekul maka viskositasnya kecil.

\section{KESIMPULAN}

1. Sediaan sampel sabun mandi cair F1 menggunakan Sodium Laureth Ether Sulfate (SLES) dengan parameter warna, aroma, kekentalan, homogenitas, uji stabilitas (oven test, room test, sun test dan cycle test), uji viskositas dan uji $\mathrm{pH}$ sesuai dengan standar.

2. Sediaan sampel sabun mandi cair F1 dari parameter uji stabilitas sun test dan oven test mengalami perubahan fisik dari kondisi awal warna putih mengkilat menjadi warna putih kekuningan mengkilat tetapi hasil parameter uji stabilitas sun test dan oven test masih masuk standar.

\section{DAFTAR PUSTAKA}

Djajadisastra. J.(2004) Cosmetic Stability disampaikan pada seminar setengah hari HIKI
Effendi, H. 2003. Telaah Kualitas Air Bagi Pengolahan Sumber Daya dan Lingkungan Perairan. Kanisius. Yogyakarta

George, E. D. dan J. A. Serdakowski. 1996. "The Formulation of Bar Soap". Dalam Soaps and Detergents A Theorittical and Pratical Review. AOCS Press, Champaign, Illinois

Ketaren, K. 1996. Pengantar Teknologi Minyak dan Lemak Pangan. Jakarta: UI Press

Pangajuanto, T. 2009. Kimia 3 : Untuk SMA/ MA Kelas XII. Pusat Perbukuan, Departemen Pendidikan Nasional, Jakarta.

Rowe, R.C. et Al. 2009. Handbook Of Pharmaceutical Excipients, $6^{\text {th }}$ Ed, The Pharmaceutical Press, London

Shipp, J. J. 1996. "Hair-care Products". Dalam Chemistry and Technology of The Cosmetics and Toiletries Industry Second Edittion. Blackie Academic \& Professional, London

Spiess, E. 1996. "Raw Materials." Dalam Chemistry and Technology of The Cosmetics and Toiletries Industry Second Edittion. Blackie Academic \& Professional, London.

Sujianti, Desmia Tri. 2010. Aplikasi Surfaktan Sodium Lauril Eter Sulfat (SLES) dan Alkil Poliglikosida (APG) Dalam Formulasi Sabun Cair. Skripsi. Tidak diterbitkan. Fakultas Teknologi Pertanian . Institut Pertanian Bogor. Bogor.

Zulkarnain, A.K., Ernawati, N. \& Sukardani, N.I., 2013, Aktivitas Amilum Bengkuang (Pachyrrizus erosus (L.) Urban) Sebagai Tabir Surya Pada Mencit dan Pengaruh Kenaikan Kadarnya Terhadap Viskositas Sediaan, Traditional Medicine Journal,18, 5-11. 